\title{
COX-2 induction by heparanase in the progression of breast cancer
}

\author{
TAKAKO IMADA $^{1}$, JUNJI MATSUOKA ${ }^{1}$, TETSUJI NOBUHISA ${ }^{1}$, TAKAOMI OKAWA ${ }^{1}$, \\ TOSHIHIRO MURATA ${ }^{1}$, YOKO TABUCHI ${ }^{1}$, YASUHIRO SHIRAKAWA ${ }^{1}$, NOBUYA OHARA ${ }^{2}$, \\ MEHMET GUNDUZ ${ }^{3}$, HITOSHI NAGATSUKA ${ }^{3}$, TATSUO UMEOKA ${ }^{4}$, YASUHISA YAMAMOTO ${ }^{4}$, \\ MOTOWO NAKAJIMA $^{5}$, NORIAKI TANAKA ${ }^{1}$ and YOSHIO NAOMOTO ${ }^{1}$
}

\author{
Departments of ${ }^{1}$ Gastroenterological Surgery, Transplant and Surgical Oncology, ${ }^{2}$ Second Pathology, \\ and ${ }^{3}$ Oral Pathology and Medicine, Graduate School of Medicine and Dentistry, Okayama University; \\ ${ }^{4}$ Ohmoto Hospital, Okayama; ${ }^{5}$ Novartis Pharma Tsukuba Institute, Tsukuba, Japan
}

Received September 30, 2005; Accepted November 11, 2005

\begin{abstract}
Breast cancer confined within the lactiferous duct or lobule, without invading the stroma, is called ductal carcinoma in situ (DCIS), whereas breast cancer that has invaded the stroma through the basal membrane is called invasive cancer. Heparanase, an endo- $\beta$-D-glucuronidase that specifically degrades heparan sulfate proteoglycans (HSPGs) in the extracellular matrix (ECM), plays an important role when breast cancer cells breach the basal membrane. Recently, we have reported that heparanase is involved in angiogenesis through direct induction of cyclo-oxygenase-2 (COX-2). COX-2 induces vascular endothelial growth factor (VEGF) and basic fibroblast growth factor (bFGF) and is thus involved in neovascularization. The present study was undertaken to analyze surgically resected breast cancer specimens for heparanase and COX-2 expression, using specimens from 59 patients with invasive cancer and 85 patients with DCIS (including 41 cases of DCIS adjacent to invasive cancer). This study yielded the following results: a) the distribution of heparanase within tumor tissue was identical to that of COX-2; b) heparanase expression was more frequent in invasive cancer than in non-invasive cancer; c) a close positive correlation was noted between heparanase and COX-2 expression (this correlation was particularly strong in cases of invasive cancer); and d) COX-2 expression was always seen in cases positive for heparanase expression. Our results indicate that heparanase expression increases during the progression of breast cancer into invasive cancer, and that this change is accompanied by
\end{abstract}

Correspondence to: Dr Yoshio Naomoto, Department of Gastroenterological Surgery, Transplant and Surgical Oncology, Graduate School of Medicine and Dentistry, Okayama University, 2-5-1 Shikatacho, Okayama 700-8558, Japan

E-mail: ynaomoto@md.okayama-u.ac.jp

Key words: heparanase, COX-2, immunohistochemistry, angiogenesis, invasion, metastasis, breast cancer increased COX-2 expression. They also suggest that heparanase may play a novel role for COX-2 mediated tumor angiogenesis in breast-cancer progression.

\section{Introduction}

Identifying the factors that predict prognosis of patients with breast cancer is important for determining postoperative therapy and for developing new methods for the treatment of breast cancer. Both heparanase and cyclo-oxygenase-2 (COX-2) are reported to be associated with the invasion and metastasis of breast cancer $(1,2)$. When ductal carcinoma in situ (DCIS) progresses into invasive cancer, cancer cells break through the basal membrane into the stroma, and the tumor increases in size through the induction of neovascularization. In this process, heparanase and COX-2 play important roles in the destruction of the basal membrane and formation of new blood vessels. Based on the assumption that heparanase and COX-2 work together when affecting the invasion and metastasis of breast cancer, we focused on the role of these two factors in invasive breast cancer in comparison to DCIS.

Heparanase specifically degrades heparan sulfate, which serves as the side-chain of heparan sulfate proteoglycans (HSPGs) (3). HSPGs are major elements of the basal membrane and extracellular matrix (ECM), and they are ubiquitous macromolecules $(4,5)$. The HSPGs of ECM function as receptors for cell adhesion (6) and as growth factors that regulate cell growth, migration and differentiation and play important roles in morphogenesis, development and tissue repair. Basal membrane HSPGs function as a barrier against cationic molecules and macromolecules. They also serve as the place for storing various cytokines and growth factors such as basic fibroblast growth factor (bFGF), vascular endothelial growth factor (VEGF), interferon- $\beta$ (INF- $\beta$ ) and transforming growth factor- $\beta$ (TGF- $\beta)(7,9)$. Therefore, if heparanase degrades heparan sulfate, an increase in the permeability across the basal membrane stimulates the release of the aforementioned cytokines and growth factors, leading to the induction of neovascularization and promotion of tumor cell migration and growth $(7,9,10)$. The expression of heparanase 
in the colon, stomach, esophagus and pancreas has been known to increase if the tumor invades the deep muscle layer or metastasizes to the lymph nodes (10-15). Heparanase activity has also been studied in tumor cell lines and been found to correlate with metastatic potential. In 1983, the first report on correlation between heparanase activity and metastatic potential was published on the basis of a study of murine B16 melanoma sublines (16). Since then, a similar relationship has been reported in various tumor cell lines $(3,17-21)$.

COX-2 is a major enzyme involved in the conversion of arachidonic acid into prostaglandins (PGs), especially PGE2. It is an intermediate response gene encoding a $71-\mathrm{kDa}$ protein. COX-2 mRNA and proteinase are undetectable in most tissues, but can be rapidly induced by proinflammatory or mitogenic stimuli, including cytokines, endotoxins, interleukins and phorbol ester (22). Excessive COX-2 expression has been reported in cancers of the colon, esophagus, lung, stomach and breast $(2,22-26)$. In a transgenic mouse model, overexpression of COX-2 in mammary epithelial cells resulted in the development of mammary tumors, indicating that COX-2 by itself can induce mammary tumorigenesis (27). Although the role of COX-2 during tumorigenesis is not yet well defined, an association between tumor COX-2 expression and angiogenic status was reported, suggesting that COX-2 may also play a role in angiogenesis (2). Tsujii and Dubois (28) showed that tumors expressing COX-2 often induce VEGF and bFGF, two growth factors associated with angiogenesis. Costa et al (2) analyzed whether COX-2 expression is associated with angiogenesis and lymph node metastasis, and concluded that COX-2 expression is associated with both processes. It is now well established that solid tumor growth is dependent on angiogenesis (27-29).

Although previous reports have shown the role of heparanase and COX-2 independently involved in tumor invasion and metastasis, we have reported that heparanase is involved in angiogenesis through direct induction of COX-2. Heparanase and COX-2 protein expression exhibited a similar pattern in esophageal tumor tissue and their expression correlated with tumor malignancy and poor survival. Their expression also revealed a significant correlation with high intratumoral microvessel density. We recently showed that upregulation of COX-2 mRNA and protein was observed in esophageal cancer cells transfected with heparanase cDNA (30). The COX-2 promoter was activated through involvement of three transcription factor (cyclic AMP responsible element, NF- $\kappa \mathrm{B}$ and NF-IL-6) binding elements in the COX-2 promoter after heparanase cDNA was transfected (30). In the current study, we analyzed surgically resected breast cancer specimens for heparanase and COX-2 expression, using specimens from 59 patients with invasive cancer and 85 patients with DCIS (including 41 cases of DCIS adjacent to invasive cancer).

\section{Materials and methods}

Tissue samples. Breast cancer tissue specimens were obtained from Okayama University Hospital or its affiliated facilities between January 2000 and October 2002. They comprised of 103 specimens including 59 patients with invasive cancer (mean age, 55.1 years; range, 26-81 years), and 44 patients with DCIS alone (mean, 54.2 years; range, 27-83 years). DCIS
Table I. Clinicopathological variables of patients with breast cancer.

$\mathrm{n}(\%)$

Tumor size (T)

Tis

$44(42.7)$

T1

$27(26.2)$

$\mathrm{T} 2$

$31(30.1)$

T3

T4

Lymph node metastasis (N)

$\mathrm{N}(-)$

$71(68.9)$

$\mathrm{N}(+)$

Unknown

Histology

Invasive ductal carcinoma

Intraductal carcinoma

Estrogen receptor

Positive

$73(70.9)$

Negative

Progesterone receptor

Positive

$70(68.0)$

Negative

$32(31.1)$

Not performed

HER2/neu

Positive

$40(38.8)$

Negative

$53(51.5)$

Not performed

$10(9.7)$

$(+)$ and (-) indicate the presence and absence of lymph node metastasis, respectively.

adjacent to invasive cancer (mean, 53.3 years; range, 26-80 years) was detected in 41 of the 59 invasive cancer cases. Of the 59 cases of invasive cancer, 27, 31, 0 and 1 were rated as $\mathrm{T} 1, \mathrm{~T} 2, \mathrm{~T} 3$ and $\mathrm{T} 4$ according to the TNM classification, respectively. Of these 59 cases, 26 had lymph node metastasis, 27 were free of lymph node metastasis, and the lymph node status of 6 was unknown. Histologically, all 59 cases of invasive cancer were ductal carcinoma. When hormone receptors were examined, 73 cases $(70.9 \%)$ were estrogen receptor-positive, and 70 cases $(65.5 \%)$ were progesterone receptor-positive (Table I).

Tissue specimens were fixed in formalin solution and embedded in paraffin. Consecutive 4-6 $\mu \mathrm{m}$ thick tissue sections were cut from paraffin blocks and placed on polylysine-coated slides for immunohistochemistry or in situ hybridization analysis. Informed consent was obtained in advance from the patients participating in this study and the study protocols were approved by the Experimental Ethics Review Committee of our institution.

Immunohistochemistry (IHC). Immunostaining for both heparanase and COX-2 was performed using the Histofine SABPO kit (Nichirei, Tokyo, Japan). Slides were deparaffinized 
and endogenous peroxidase activity was blocked by incubation in $3 \% \mathrm{H}_{2} \mathrm{O}_{2}$ in methanol for $10 \mathrm{~min}$ at room temperature. Slides were microwaved in $10 \mathrm{mM}$ citrate buffer ( $\mathrm{pH}$ 6.0) for 5 min for antigen retrieval. Non-specific binding was then blocked with avidin followed by biotin for $10 \mathrm{~min}$ each. Anti-human heparanase mouse IgG monoclonal antibody ${ }^{13}$ was applied at a dilution of 1:500 in PBS. Anti-human COX-2 mouse IgG monoclonal antibody (IBL, Gunma, Japan) was applied at a dilution of 1:20 in PBS. Slides were incubated overnight at $4{ }^{\circ} \mathrm{C}$. The biotinylated secondary $\operatorname{IgG}$ antibody (Histofine SAB-PO kit; Nichirei) was applied for $10 \mathrm{~min}$ at room temperature, and streptavidin conjugated to peroxidase (Histofine SAB-PO kit) was applied for $5 \mathrm{~min}$ at room temperature. Chromogen 3,3'-diaminobenzidine (Histofine DAB substrate kit; Nichirei) was subsequently added, and the color reaction was observed under light microscopy. The reaction was stopped by immersing the slides in deionized water. Slides were then counter-stained with Mayer's hematoxylin and mounted. Three examiners, who were blinded to the clinical data, rated the tissue section under microscopy. Cases where tumor cells accounted for $\geq 10 \%$ of the total cells, or those where the invasive front was intensely stained, were rated as positive.

Tissue and probe preparation for in situ hybridization. The specimens were immersed in $4 \%$ paraformaldehyde solution in phosphate buffer. All fixed specimens were embedded in paraffin and $4-\mu \mathrm{m}$ thick sections were prepared. Digoxigenin11-UTP-labeled single strand RNA probes were prepared using a DIG Labeling Kit (Roche Diagnostics, Penzberg, Germany) according to the instructions provided by the manufacturer. For generation of the heparanase probe, a 571-bp fragment of human heparanase cDNA [bases 261-832 of the total cDNA (GeneBank accession no. AF144325)] was obtained by reverse transcription followed by polymerase chain reaction (RTPCR) and was subcloned into pCR21 (Invitrogen, San Diego, CA). For generation of the COX-2 probe, a 304-bp fragment of human COX-2 cDNA [bases 574-878 of the total cDNA (GeneBank accession no. UO4636)] was obtained by reverse transcription followed by RT-PCR and was subcloned into pCR21 (Invitrogen).

In situ hybridization procedure. The sections were deparaffinized, rehydrated and incubated with $3 \mathrm{mg} / \mathrm{ml}$ of proteinase K (Roche Diagnostics, Tokyo, Japan) in $10 \mathrm{mM}$ Tris- $\mathrm{HCl}(\mathrm{pH} 8.0) 1 \mathrm{mM}$ EDTA for $10 \mathrm{~min}$ at $37^{\circ} \mathrm{C}$. Acetylation of the sections was performed by incubating with freshly prepared $0.25 \%$ aceticanhydride in $0.1 \mathrm{M}$ triethanolamine$\mathrm{HCl}$ buffer ( $\mathrm{pH} \mathrm{8.0)}$ for $10 \mathrm{~min}$ at room temperature.

The hybridization solution contained $50 \%$ deionized formamide, $10 \%$ dextran sulfate, $1 \mathrm{X}$ Dehardt's solution, $600 \mathrm{mM} \mathrm{NaCl}, 0.25 \%$ SDS, $250 \mathrm{mg}$ per $\mathrm{ml}$ of E. coli tRNA (proteinase treated) $10 \mathrm{mM}$ DTT (idithiothreitol), and 0.1 $2.0 \mathrm{mg} / \mathrm{ml}$ of digoxigenin-UTP-labeled RNA probe. The probe was placed on the sections, covered with parafilm and incubated at $50^{\circ} \mathrm{C}$ for $16 \mathrm{~h}$ in a moisture chamber. After hybridization, the slides were incubated with $50 \%$ formamide in $2 \mathrm{X} \mathrm{SSC}$ for $30 \mathrm{~min}$ at $50^{\circ} \mathrm{C}$ to remove the excess probe. The slides were incubated with $2 \mathrm{X} \mathrm{SSC}$ and $0.2 \mathrm{X}$ SSC for 15 min twice at $50^{\circ} \mathrm{C}$.
The washed slides were incubated with DIG buffer 1 (100 mM Tris- $\mathrm{HCl} \mathrm{pH} \mathrm{7.5,} 150 \mathrm{mM} \mathrm{NaCl}$ ) for $60 \mathrm{~min}$ at room temperature. A $100-\mathrm{ml} / \mathrm{cm}^{2}$ specimen of diluted polyclonal sheep anti-digoxigenin Fab fragment (1:1000) in DIG buffer 1 was mounted on the sections, and incubated for $30 \mathrm{~min}$ at room temperature. Coloring solution containing $337.5 \mathrm{mg} / \mathrm{ml}$ of NBT and $165 \mathrm{mg} / \mathrm{ml}$ of BCIP in DIG buffer $3(100 \mathrm{mM}$ Tris- $\mathrm{HCl} \mathrm{pH} 9.5,100 \mathrm{mM} \mathrm{NaCl}, 50 \mathrm{mM} \mathrm{MgCl}$ ) was mounted on the sections and incubated at room temperature or $37^{\circ} \mathrm{C}$ until the signal-noise ratio was maximum. The slides were mounted with counterstaining by methyl green. The controls included: a) hybridization with the sense (mRNA) probe; b) RNase treatment $(20 \mathrm{mg} / \mathrm{ml})$ hybridization; and c) use of neither antisense nor antidigoxigenin antibody. None of the controls showed positive signals.

Statistical analysis. We examined the correlation between the expression of heparanase/COX-2 and various clinicopathological parameters using Mann-Whitney's U test. Fisher's exact probability test was used to examine the association between heparanase and COX-2 expression. A $\mathrm{P}$-value $<0.05$ denoted the presence of a statistically significant difference.

\section{Results}

Immunohistochemistry. In cases of invasive cancer, an intense chromatic response for heparanase was noted in the cytoplasm of cancer cells. Stromal tissue did not show such an intense chromatic response. Within the same tumor tissue, the area adjacent to the stroma, i.e. the invasive front, was intensely stained. When stained for COX-2, an intense chromatic response was also seen in the cytoplasm of cancer cells. As shown in Fig. 1a, b, e, and f, the area positively stained for heparanase was identical to that positively stained for COX-2. In addition, in cases of DCIS, in which both heparanase and COX-2 were positive, the area positively stained for heparanase was identical to the area positively stained for COX-2 (Fig. 1c and g).

Heparanase and clinicopathological characteristics. The expression of heparanase was analyzed in relation to clinicopathological characteristics (Table II). The mean age of heparanase-positive patients (52.1 years) tended to be lower than that of heparanase-negative patients (56.1 years), although this difference was not statistically significant. The tumor sizes were not significantly different between the heparanasepositive and -negative groups. The heparanase-positive rate was significantly higher for lymph node metastasis-positive cases $(57.7 \%)$ than for lymph node metastasis-free cases $(23.9 \%)(\mathrm{P}=0.001839)$. When the relationship between heparanase and hormone receptors was analyzed, the heparanase-positive rate did not show a statistically significant difference with regard to the presence or absence of estrogen or progesterone receptors in tumor. The expression of HER2/ neu also did not show a statistically significant difference between the heparanase-positive and -negative groups.

COX-2 and clinicopathologic characteristics. Table III shows the relationship between COX-2 expression and 


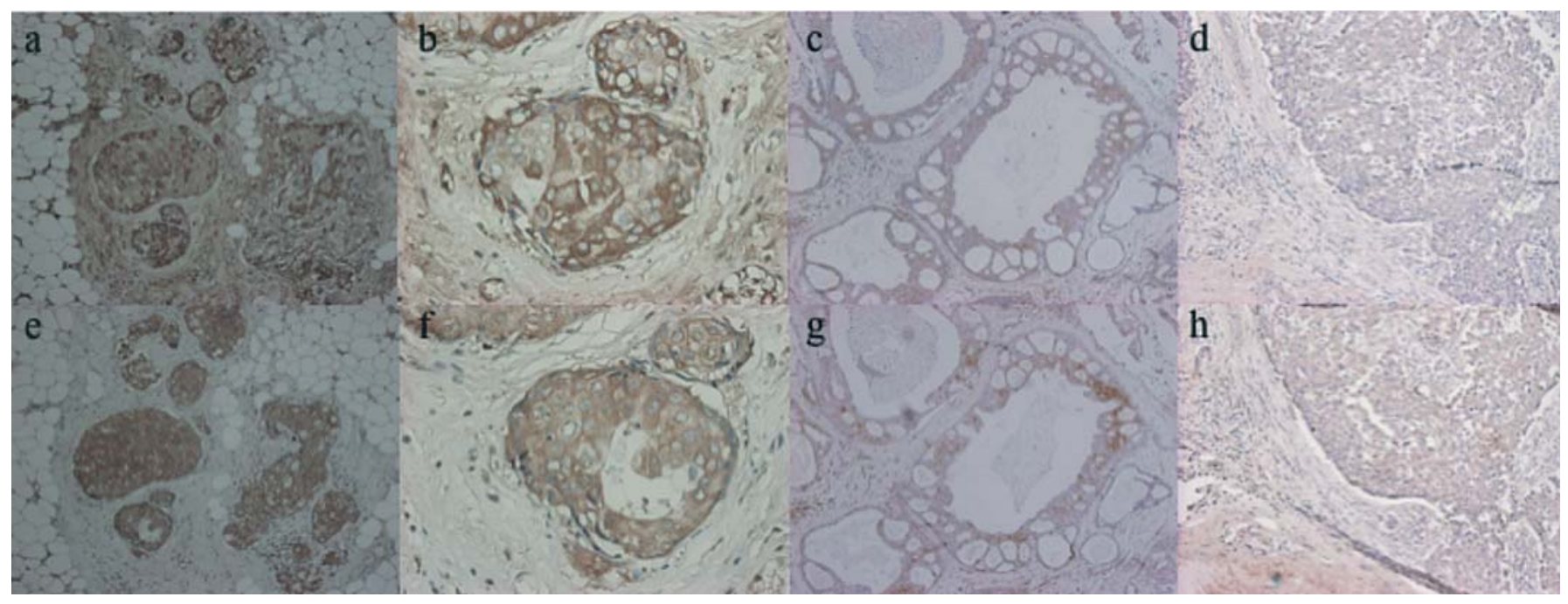

Figure 1. Immunohistochemical staining of heparanase and COX-2 proteins in breast cancer tissue. Heparanase immunoreactivity (a-d), and COX-2 immunoreactivity (e-h). (a and e) Magnification x100; heparanase and COX-2 were intensely stained at the invasive front. (b and f) Magnification x400; (c and g) magnification x100; heparanase and COX-2 were stained at the same area in DCIS. (d and h) Magnification x100; negative controls for heparanase and COX-2.

Table II. Heparanase expression and clinicopathological characteristics of patients with breast cancer.

\begin{tabular}{lccc}
\hline & Total & P-value \\
\hline Age & \multicolumn{3}{c}{ Median age } \\
Heparanase (+) & 35 & 52.11 & \\
Heparanase (-) & 68 & 56.06 & $0.135853^{\mathrm{a}}$ \\
& & Heparanase & \\
Tumor size (T) & & positive (\%) & \\
T1 & 27 & $15(55.6)$ & $0.370264^{\mathrm{a}}$
\end{tabular}

Lymph node

metastasis $(\mathrm{N})$

$\begin{array}{llrr}\mathrm{N}(-) & 71 & 17(23.9) & \\ \mathrm{N}(+) & 26 & 15(57.7) & 0.001839^{\mathrm{a}} \\ \quad \text { Estrogen receptor } & & & \\ \quad \begin{array}{l}\text { Positive } \\ \text { Negative }\end{array} & 73 & 27(37.0) & \\ \text { P } & 30 & 8(26.7) & 0.317424^{\mathrm{a}}\end{array}$

Progesterone

receptor

\begin{tabular}{lrrr} 
Positive & 70 & $26(37.1)$ & \\
Negative & 32 & $8(25.0)$ & $0.229678^{\mathrm{a}}$ \\
HER2/neu & & & \\
Positive & 40 & $17(42.5)$ & \\
Negative & 53 & $16(30.2)$ & $0.161719^{\mathrm{a}}$ \\
\hline
\end{tabular}

$(+)$ and (-) indicate the presence and absence of heparanase expression or lymph node metastasis, respectively. ${ }^{\mathrm{a} M a n n-W h i t n e y ' s ~ U ~ t e s t . ~}$

clinicopathological characteristics. The mean age of COX-2positive patients (53.4 years) was lower than that of COX-2negative patients (56.7 years), although this difference was
Table III. COX-2 expression and clinicopathological characteristics of patients with breast cancer.

\begin{tabular}{|c|c|c|c|}
\hline & Total & & P-value \\
\hline Age & & Median age & \\
\hline COX-2(+) & 63 & 53.44 & \\
\hline COX-2 (-) & 40 & 56.73 & $0.268137^{\mathrm{a}}$ \\
\hline Tumor size $(\mathrm{T})$ & & DX-2 positive (\%) & \\
\hline $\mathrm{T} 1$ & 27 & 18 (66.7) & \\
\hline$\geq \mathrm{T} 2$ & 32 & $20(62.5)$ & $0.74126^{\mathrm{a}}$ \\
\hline \multicolumn{4}{|l|}{$\begin{array}{l}\text { Lymph node } \\
\text { metastasis }(\mathrm{N})\end{array}$} \\
\hline $\mathrm{N}(-)$ & 71 & $39(54.9)$ & \\
\hline $\mathrm{N}(+)$ & 26 & $19(73.1)$ & $0.108215^{\mathrm{a}}$ \\
\hline \multicolumn{4}{|c|}{ Estrogen receptor } \\
\hline Positive & 73 & $46(63.0)$ & \\
\hline Negative & 30 & $17(56.7)$ & $0.550123^{\mathrm{a}}$ \\
\hline \multicolumn{4}{|l|}{$\begin{array}{l}\text { Progesterone } \\
\text { receptor }\end{array}$} \\
\hline Positive & 70 & $42(60.0)$ & \\
\hline Negative & 32 & $20(62.5)$ & $0.811276^{\mathrm{a}}$ \\
\hline \multicolumn{4}{|l|}{ HER2/neu } \\
\hline Positive & 40 & $27(67.5)$ & \\
\hline Negative & 53 & $32(60.4)$ & $0.407948^{\mathrm{a}}$ \\
\hline
\end{tabular}

not statistically significant. Tumor size also did not show a statistically significant difference between the COX-2positive and -negative groups. The COX-2-positive rate was higher for the lymph node metastasis-positive group (73.1\%) 
Table IV. Analysis of heparanase and COX-2 expression by immunohistochemistry in invasive and intraductal breast cancers.

\begin{tabular}{lccc}
\hline & Total & $\begin{array}{c}\text { Heparanase } \\
\text { positive (\%) }\end{array}$ & P-value \\
\hline $\begin{array}{l}\text { Heparanase } \\
\text { Invasive cancer }\end{array}$ & 59 & $28(47.5)$ & \\
DCIS $^{\text {a }}$ & 85 & $14(16.5)$ & $<0.001^{\text {b }}$ \\
\hline & Total & COX-2 & P-value \\
& & positive (\%) & \\
& & $38(64.4)$ & \\
\hline COX-2 & 59 & $51(60.0)$ & $0.593761^{\text {b }}$ \\
$\begin{array}{l}\text { Invasive cancer } \\
\text { DCIS }\end{array}$ & 85 & & \\
\hline $\begin{array}{l}\text { ancluding DCIS alone and DCIS adjacent to invasive cancer. }{ }^{\mathrm{b}} \text { Mann- } \\
\text { Whitney's U test. }\end{array}$ & & \\
\hline
\end{tabular}

than for the lymph node metastasis-free group (54.9\%), although this difference was not significant. When the relationship between COX-2 and the hormone receptors was analyzed, the COX-2-positive rate did not show a statistically significant difference with regard to the presence or absence of estrogen or progesterone receptors in the tumor. The expression of HER2/neu did not show a statistically significant difference between the COX-2-positive and -negative groups.

Heparanase and COX-2. The expression of heparanase and COX-2 was then compared between invasive cancer and DCIS. The heparanase-positive rate was higher for invasive cancer $(47.5 \%)$ than for DCIS $(16.5 \%)(\mathrm{P}<0.001)$, indicating that heparanase expression increases as tumors become invasive (Table IV). On the other hand, the COX-2-positive rate did not differ between DCIS $(60.0 \%)$ and invasive cancer $(64.4 \%)(\mathrm{P}=0.593761)$ (Table IV). When the relationship between heparanase expression and COX-2 expression was analyzed for cases of invasive cancer, cases of DCIS adjacent to invasive cancer and cases of DCIS alone, a significant correlation between heparanase and COX-2 expression was noted in all three groups $(\mathrm{P}<0.05)$. The percentage of cases showing expression of both heparanase and COX-2 was approximately $16 \%$ in the DCIS group and $47.5 \%$ in the invasive cancer group, and the correlation between heparanase and COX-2 expression was stronger in the case of invasive cancer (Table V). None of the cases of DCIS and invasive cancer was heparanase-positive but COX-2-negative. Thus, COX-2 was expressed in all heparanase-positive cases, but COX-2 expression was not always accompanied by heparanase expression. These findings suggest that the expression of COX-2 is dependent on heparanase.

In situ hybridization. In situ hybridization was performed on 16 cases of invasive cancer and 6 cases of DCIS. When examined by in situ hybridization, granular chromatic responses of cytoplasm were noted in the area that had been positively stained for heparanase and COX-2 on immunohistochemistry (Fig. 2). In the immunohistochemical analysis
Table V. Correlation of heparanase and COX-2 expression by IHC in human breast cancer.

\begin{tabular}{|c|c|c|c|}
\hline \multirow[b]{2}{*}{ COX-2 } & \multicolumn{3}{|c|}{ Invasive cancer } \\
\hline & Positive (\%) & & Negative $(\%)$ \\
\hline \multicolumn{4}{|l|}{ Heparanase } \\
\hline Positive & $28(47.5)$ & \multirow[t]{2}{*}{$\mathrm{P}<0.001^{\mathrm{a}}$} & 0 \\
\hline \multirow[t]{2}{*}{ Negative } & $10(16.9)$ & & $21(35.6)$ \\
\hline & \multicolumn{3}{|c|}{ DCIS adjacent to invasive cancer } \\
\hline COX-2 & Positive (\%) & & Negative $(\%)$ \\
\hline \multicolumn{4}{|l|}{ Heparanase } \\
\hline Positive & $7(17.1)$ & \multirow[t]{2}{*}{$\mathrm{P}=0.029259^{\mathrm{a}}$} & 0 \\
\hline \multirow[t]{2}{*}{ Negative } & $19(46.3)$ & & $15(36.6)$ \\
\hline & \multicolumn{3}{|c|}{ DCIS alone } \\
\hline COX-2 & Positive (\%) & & Negative $(\%)$ \\
\hline \multicolumn{4}{|l|}{ Heparanase } \\
\hline Positive & 7 (15.9) & \multirow[t]{2}{*}{$\mathrm{P}=0.012544^{\mathrm{a}}$} & 0 \\
\hline Negative & $18(40.9)$ & & $19(43.2)$ \\
\hline
\end{tabular}

${ }^{\text {a}}$ Fisher's exact probability test.

and in situ hybridization, both cancer cells and inflammatory cells were positively stained for heparanase and COX-2.

\section{Discussion}

Lymph node metastasis, low age, tumor size, negativity for hormone receptors and degree of nuclear atypism have been known to serve as indicators of the malignancy level in breast cancer. More recently, HER2 expression has been viewed as an indicator of breast malignancy. When the results of the present study were analyzed in relation to these indicators of malignancy, a positive correlation was noted between heparanase expression and lymph node metastasis, while heparanase expression did not correlate with age, tumor size, hormone receptors or HER2 status. Heparanase expression has been reported for various tumor cells, inflammatory cells and normal cells adjacent to tumor cells. A positive correlation between heparanase expression and malignancy level and a negative correlation between heparanase expression and survival rate have been reported for various tumors including our studies $(1,10,12-15)$. With respect to the relationship of heparanase expression and lymph node metastasis, a markedly higher incidence of heparanase expression in lymph node metastasis-positive cases than in lymph node metastasis-free cases has been reported for breast cancer by Maxhimer et al (1) and for bladder cancer by Gohji et al (15), consistent with our present results. With regard to the relationship with tumor diameter, Gohji et al (15) reported a significantly higher incidence of heparanase expression in stage pT3 or higher stage cases of bladder cancer $(85 \%)$ than for stage pT2 bladder cancer (25\%). Maxhimer et al (1) also reported a correlation 


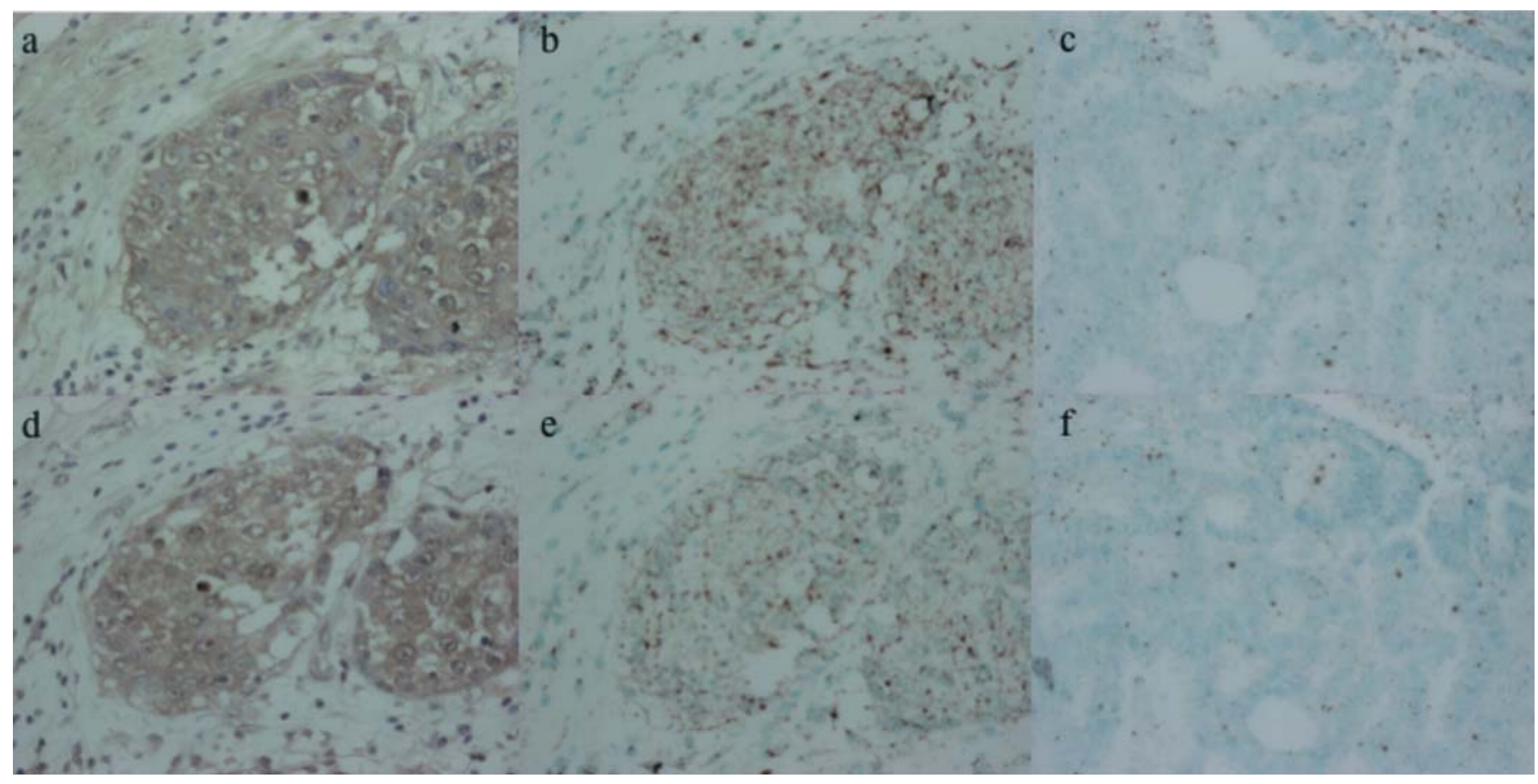

Figure 2. In situ hybridization of heparanase and COX-2 mRNA in breast cancer tissues (b, c, e and f) (x400). Heparanase (b and c), and COX-2 (e and f). Immunohistochemical staining of heparanase (a) and COX-2 (d) (x400). (a, b, d and e) Heparanase and COX-2 were positive in the same area by both immunohistochemical staining and $i n$ situ hybridization in breast cancer. (c and f) Negative case.

between heparanase expression and tumor diameter in cases of breast cancer. In the present study, heparanase expression tended to be seen in the tumor invasion front, but no correlation was noted between heparanase expression and tumor diameter. With respect to hormone receptors, the report of Maxhimer et al (1) showed no correlation between hormone receptors and heparanase expression, consistent with our present results. Regarding the relationship with survival rate, a significantly lower survival rate for heparanase-positive cases has been reported for pancreas, stomach, esophagus and colorectal cancers (10-14). The present study revealed a higher incidence of heparanase expression in invasive cancer, compared to non-invasive cancer, strongly suggesting that heparanase is associated with breast cancer invasion.

On the other hand, the relationship of COX-2 expression with the potential of breast cancer metastasis and invasion (mediated by vascularization) and with malignancy level has also been reported for various tumor types $(2,26)$. Costa et al (2) reported a relationship of COX-2 expression with lymph node metastasis and a short disease-free survival in breast cancer. Denkert et al (31) found a significant correlation between COX-2 expression and tumor size, lymph node metastasis, and a low disease-free and overall survival in the analysis of 221 cases of breast cancer. Although Shim et al (32) reported that COX-2 expression correlated with nuclear grade in DCIS and normal adjacent epithelium of breast cancer, we could not detect a similar relationship in this study. Some epidemiological studies showed that periodical oral treatment with NSAIDs, which inhibit COX enzymes, reduced the onset of breast cancer and colorectal cancer. Like heparanase expression, COX-2 expression may serve as an indicator of malignancy, and its suppression may lead to improvement in the survival rate of patients. For breast cancer, it has been known that COX-2 expression decreases as DCIS advances into invasive cancer. In the present study, however, COX-2 expression did not differ between DCIS and invasive cancer. Furthermore, the incidence of COX-2 expression in DCIS coexistent with invasive cancer was equivalent to that in invasive cancer.

Our analysis showed a positive correlation between heparanase expression and COX-2 expression in both invasive breast cancer and DCIS of the breast. Among all cases of DCIS, $\geq 40 \%$ were only COX-2-positive, and $16 \%$ were both heparanase- and COX-2-positive (approximately one-third of the number of COX-2-positive only cases). In the invasive cancer group, $47.5 \%$ of all cases were both heparanase- and COX-2-positive, and $17 \%$ were only COX-2-positive. Thus, the correlation between heparanase and COX-2 expression was stronger in cases of invasive cancer than in cases of DCIS.

As stated above, both heparanase and COX-2 are involved in angiogenesis. The results from the present study suggest that, as cancer advances, both heparanase and COX-2 are expressed in close correlation with each other, and their synergistic effects on angiogenesis guide the tumor to become invasive. In the invasive cancer group, the DCIS adjacent to invasive cancer group and the DCIS alone group, heparanasepositive cases were always COX-2-positive, and there was no case where only heparanase was positive and COX-2 was negative. On the other hand, COX-2-positive but heparanasenegative cases accounted for $17 \%$ of the invasive cancer group and $40 \%$ of the DCIS group. Thus, heparanase expression was always accompanied by COX-2 expression, but not vice versa. This is the first study to report the apparent heparanasedependent COX-2 expression. The higher incidence of COX-2 expression compared with that of heparanase expression in early stages of breast carcinogenesis suggests that COX-2 
expression is induced not only by heparanase but also by mitogenic stimuli such as known proinflammatory cytokines, endotoxins, interleukins and phorbol ester. It also suggests that COX-2 expression stimulates vascularization and thus contributes to the proliferation and invasion of tumors. Considering that heparanase expression increases as cancer advances, and that a close correlation between heparanase and COX-2 is evident, it seems that the expression of COX-2 is more dependent on heparanase in advanced cancer than in DCIS. When breast cancer advances from DCIS to invasive cancer, it is likely that heparanase degrades the ECM, induces the release of various cytokines and growth factors such as bFGF, VEGF, KGF, INF- $\beta$ and TGF- $\beta$, and contributes to vascularization through the induction of $\mathrm{COX}-2$ and is thus closely involved in the progression of cancer.

In the present study, we examined the relationship between heparanase and COX-2 expression using surgically resected breast cancer specimens. Although some previous reports have separately analyzed heparanase or COX-2 in relation to invasion and metastasis of breast cancer $(1,2)$, the present study is the first in which both heparanase and COX-2 were analyzed simultaneously. This study revealed that: a) the distribution of heparanase in tumor tissue was identical to that of COX-2 (the invasive front showed particularly intense chromatic responses for both heparanase and $\mathrm{COX}-2)$; b) heparanase expression correlated closely with COX-2 expression (the correlation was particularly strong in invasive cancer); and c) heparanase-expressing cases always coexpressed with COX-2. These results allow us to conclude that COX-2 expression is, at least, partly dependent on heparanase.

\section{Acknowledgements}

We thank T. Yamanishi, K. Nasu, and Y. Shirakiya for their technical support.

\section{References}

1. Maxhimer JB, Quiros RM, Stewart R, Dowlatshahi K, Gattuso P, Fan M, Prinz RA and Xu X: Heparanase- 1 expression is associated with metastatic potential of breast cancer. Surgery 132: 326-333, 2002.

2. Costa C, Soares R, Reis-Filho JS, Leitao D, Amendoeira I and Schmitt FC: COX-2 expression is associated with angiogenesis and lymph node metastasis in human breast cancer. J Clin Pathol 55: 429-434, 2002.

3. Nakajima M, Irimura T and Nicolson GL: Heparanase and tumor metastasis. J Cell Biochem 36: 157-167, 1988.

4. Kjellen L and Lindahl U: Proteoglycans: structures and interactions. Annu Rev Biochem 60: 443-475, 1991.

5. David G: Integral membrane heparan sulfate proteoglycan. FASEB J 7: 1023-1030, 1993

6. Goldshmidt O, Zcharia E, Cohen M, Aingorn H, Cohen I, Nadav L, Katz BZ, Geiger B and Vlodavsky I: Heparanase mediates cell adhesion independent of its enzymatic activity. FASEB J 17: 1015-1025, 2003.

7. Vlodavsky I, Miao HQ, Medalion B, Danagher P and Ron D: Involvement of heparan sulfate and related molecules in sequestration and growth promoting activity of fibroblast growth factor. Cancer Metastasis Rev 15: 177-186, 1996.

8. Ohen T, Gitay-Goren H, Sharon R, Shibuya M, Halaban R, Levi BZ and Neufeld G: VEGF121, a vascular endothelial growth factor (VEGF) isoform lacking heparin binding ability, requires cell-surface heparan sulfate for efficient binding to the VEGF receptors of human melanoma cells. J Biol Chem 270: 11322-11326, 1995.
9. Vlodavsky I, Bar-Shavit R, Ishai-Michaeli R, Bashkin P and Fuks Z: Extracellular sequestration and release of fibroblast growth factor: a regulatory mechanism? Trends Biochem Sci 16: 268-271, 1991.

10. Koliopanos A, Friess H, Kleeff J, Shi X, Liao Q, Pecker I, Vlodavsky I, Zimmermann A and Buchler MW: Heparanase expression in primary and metastatic pancreatic cancer. Cancer Res 61: 4655-4659, 2001.

11. Friedmann Y, Vlodavsky I, Aingorn H, Aviv A, Peretz T, Pecker I and Pappo O: Expression of heparanase in normal, dysplastic, and neoplastic human colonic mucosa and stroma: evidence for its role in colonic tumorigenesis. Am J Pathol 157: 1167-1175, 2000.

12. Nobuhisa T, Naomoto Y, Ohkawa T, Takaoka M, Ono R, Murata T, Gunduz M, Shirakawa Y, Yamatsuji T, Haisa M, Matsuoka J, Tsujigiwa H, Nagatsuka H, Nakajima M and Tanaka N: Heparanase expression correlates with malignant potential in human colon cancer. J Cancer Res Clin Oncol 131: 229-237, 2005.

13. Takaoka M, Naomoto Y, Ohkawa T, Uetsuka H, Shirakawa Y, Uno F, Fujiwara T, Gunduz M, Nagatsuka H, Nakajima M, Tanaka N and Haisa M: Heparanase expression correlates with invasion and poor prognosis in gastric cancers. Lab Invest 83: 613-622, 2003.

14. Ohkawa T, Naomoto Y, Takaoka M, Nobuhisa T, Noma K, Motoki T, Murata T, Uetsuka H, Kobayashi M, Shirakawa Y, Yamatsuji T, Matsubara N, Matsuoka J, Haisa M, Gunduz M, Tsujigiwa H, Nagatsuka $H$, Hosokawa $M$, Nakajima $M$ and Tanaka N: Localization of heparanase in esophageal cancer cells: respective roles in prognosis and differentiation. Lab Invest 84: 1289-1304, 2004.

15. Gohji K, Hirano H, Okamoto M, Kitazawa S, Toyoshima M, Dong J, Katsuoka Y and Nakajima M: Expression of three extracellular matrix degradative enzymes in bladder cancer. Int J Cancer 95: 295-301, 2001.

16. Nakajima M, Irimura T, Di Ferrante D, Di Ferrante $\mathrm{N}$ and Nicolson GL: Heparan sulfate degradation: relation to tumor invasive and metastatic properties of mouse B16 melanoma sublines. Science 220: 611-613, 1983.

17. Parish CR, Freeman C and Hulett MD: Heparanase: a key enzyme involved in cell invasion. Biochim Biophys Acta 1471: M99-M108, 2001.

18. Vlodavsky I, Mohsen M, Lider O, Svahn CM, Ekre HP, Vigoda M, Ishai-Michaeli R and Peretz T: Inhibition of tumor metastasis by heparanase inhibiting species of heparin. Invasion Metastasis 14: 290-302, 1994.

19. Vlodavsky I, Friedmann Y, Elkin M, Aingorn H, Atzmon R, Ishai-Michaeli R, Bitan M, Pappo O, Peretz T, Michal I, Spector L and Pecker I: Mammalian heparanase: gene cloning, expression and function in tumor progression and metastasis. Nat Med 5: 793-802, 1999.

20. Hulett MD, Freeman C, Hamdorf BJ, Baker RT, Harris MJ and Parish CR: Cloning of mammalian heparanase, an important enzyme in tumor invasion and metastasis. Nat Med 5: 803-809, 1999.

21. Kosir MA, Wang W, Zukowski KL, Tromp G and Barber J: Degradation of basement membrane by prostate tumor heparanase. J Surg Res 81: 42-47, 1999.

22. Zimmermann KC, Sarbia M, Weber AA, Borchard F, Gabbert HE and Schror K: COX-2 expression in human esophageal carcinoma. Cancer Res 59: 198-204, 1999.

23. Soslow RA, Dannenberg AJ, Rush D, Woerner BM, Khan KN, Masferrer $\mathbf{J}$ and Koki AT: COX-2 is expression in human pulmonary, colonic, and mammary tumors. Am Cancer Soc 89: $2637-2645,2000$

24. Ristimaki A, Honkanen N, Jankala H, Sipponen P and Harkonen M: Expression of COX-2 in human gastric carcinoma. Cancer Res 57: 1276-1280, 1997.

25. Wilson KT, Fu S, Ramanujam KS and Meltzer SJ: Increased expression of inducible nitric oxide synthase and COX-2 in Barrett's esophagus and associated adenocarcinomas. Cancer Res 58: 2929-2934, 1998.

26. Hida T, Yatabe Y, Achiwa H, Muramatsu H, Kozaki K, Nakamura S, Ogawa M, Mitsudomi T, Sugiura T and Takahashi T: Increased expression of COX-2 occurs frequently in human lung cancers, specifically in adenocarcinomas Cancer Res 58: 3761-3764, 1998.

27. Liu CH, Chang SH, Narko K, Trifan OC, Wu MT, Smith E, Haudenschild C, Lane TF and Hla T: Overexpression of COX-2 is sufficient to induce tumorigenesis in transgenic mice. J Biol Chem 276: 18563-18569, 2001. 
28. Tsujii M and Dubois RN: Alterations in cellular adhesion and apoptosis in epithelial cells overexpressing prostaglandin endoperoxide synthase 2. Cell 83: 493-501, 1995 .

29. Fox SB, Gatter KC and Harris AL: Tumor angiogenesis. J Pathol 179: 232-237, 1996.

30. Okawa T, Naomoto Y, Nobuhisa T, Takaoka M, Motoki T, Shirakawa Y, Yamatsuji T, Inoue H, Ouchida M, Gunduz M, Nakajima $\mathrm{M}$ and Tanaka $\mathrm{N}$ : Heparanase is involved in angiogenesis in esophageal cancer through induction of cyclooxygenase-2. Clin Cancer Res 11: 7995-8005, 2005.
31. Denkert C, Winzer KJ, Muller BM, Weichert W, Pest S, Kobel M, Kristiansen G, Reles A, Siegert A, Guski H and Hauptmann S: Elevated expression of cyclooxgenase-2 is a negative prognostic factor for disease-free survival and overall survival in patients with breast carcinoma. Cancer 97: 2978-2987, 2003.

32. Shim V, Gauthier ML, Sudilovsky D, Mantei K, Chew KL, Moore DH, Cha I, Tlsty TD and Esserman LJ: Cyclooxgenase-2 expression is related to nuclear grade in ductal carcinoma in situ and is increased in its normal adjacent epithelium. Cancer Res 63: 2347-2350, 2003. 